\title{
The Effect of Deep Friction Massage versus Stretching of Wrist Extensor Muscles in the Treatment of Patients with Tennis Elbow
}

\author{
Sahar Mahmoud Hassan"1, Ashraf Ramadan Hafez ${ }^{2 *}$, Hamada Eid Seif1, \\ Shaji John Kachanathu ${ }^{3}$ \\ ${ }^{1}$ Cairo University Hospital, Cairo University, Egypt \\ ${ }^{2}$ Faculty of Physical Therapy, Deraya University, Alminya Algadida, Egypt \\ ${ }^{3}$ Collage of Applied Medical Sciences, King Saud University, Riyadh, Saudi Arabia \\ Email: *ashrafrh1989@yahoo.com
}

Received 25 January 2016; accepted 23 February 2016; published 26 February 2016

Copyright (C) 2016 by authors and Scientific Research Publishing Inc.

This work is licensed under the Creative Commons Attribution International License (CC BY). http://creativecommons.org/licenses/by/4.0/

\section{(c) (i) Open Access}

\begin{abstract}
Overuse injuries of the elbow and forearm are very common in athletes. This study was conducted to evaluate the effect of muscle stretching and deep friction massage with using wrist joint support during management of tennis elbow. This study included forty patients with tennis elbow divided into two equal groups: the first group with a mean age $38.1 \pm 0.294$ followed a physical therapy program in form of deep friction massage on the proximal attachment of wrist extensor muscles, the second group with a mean age $37.6 \pm 0.253$, submitted to stretching exercises of wrist extensors. Both of groups submitted to ultrasonic therapy with wrist splint during treatment period, three sessions per week for six weeks. Outcome measures were universal goniometer, visual analogue scale, and squeezing sphygmomanometer. The results showed that there was a significant improvement in ROM of wrist flexion and wrist extension, and handgrip in second group and it was more than in the first group while no significant difference in pain. This study showed that stretching exercise is more beneficial in the management of patients with tennis elbow.
\end{abstract}

\section{Keywords}

Tennis Elbow, Stretching Exercises of Wrist Extensors, Ultrasonic Therapy and Deep Friction Massage, Splinting

\footnotetext{
${ }^{*}$ Corresponding author.
}

How to cite this paper: Hassan, S.M., Hafez, A.R., Seif, H.E. and Kachanathu, S.J. (2016) The Effect of Deep Friction Massage versus Stretching of Wrist Extensor Muscles in the Treatment of Patients with Tennis Elbow. Open Journal of Therapy and Rehabilitation, 4, 48-54. http://dx.doi.org/10.4236/ojtr.2016.41004 


\section{Introduction}

Tennis elbow (TE) is known as Lateral Epicondylitis (LE) or inflammation of the outside portion of the elbow presenting with soreness and tenderness. Lateral epicondylitis is one of the most common causes of elbow and forearm pain encountered in clinical practice commonly associated with resistant wrist or finger extension and gripping activities [1]. Tennis elbow affects $1 \%$ to $3 \%$ of the adult population, and it occurs mainly as episodes in the dominant arm of patients aged 35 to 50 years, and is equally distributed between men and women [2]-[4].

Tennis elbow is a painful and disabling musculoskeletal condition predominant in the range from 35 to 50 ages, and often causes considerable pain in normal daily activities such as gripping and carrying and lifting. Tennis elbow is traditionally considered to be self-limiting, but may last for 6 - 18 months. Its estimated prevalence in the general population is $3 \%-7 \%$ [5]. However, workers undertaking repetitive tasks are at greater risk, representing between $35 \%$ - $64 \%$ of all cases [6].

Tennis elbow is a common disorder amongst tennis players because all individuals are exposed to repetitive stress on the wrist extensors and they are at risk for developing the condition. The diagnosis of tennis elbow is based on clinical examination. However, in chronic cases, ultrasound, radiographic examination, and MRI may be useful to exclude other causes of lateral elbow pain [7] [8].

Conventional treatment for tennis elbow has focused primarily on the pain management by anti-inflammatory medication, ultrasound, phonophoresis [9], or iontophoresis. Various treatments have been attempted for tennis elbow including corticosteroid injection [10], electrical stimulation [11], acupuncture [12], and splint. Surgical treatment is indicated in 5\% - 10\% [13] of patients who did not improve from their symptoms with conservative treatment approach.

The conventional treatment intervention of tennis elbow is most often accompanied by exercise program which may include strengthening, flexibility, or endurance training exercises. For instance, Stasinopoulos et al. [14] recommended the use of static stretching of the Extensor Carpi Radialis Brevis (ECRB) and eccentric strengthening exercises for the wrist extensors in treating lateral epicondylitis. The early return of functional status is very useful for a sports person, as it will facilitate his/her return to sports in less duration. This improvement in functional status will also prevent disuse atrophy or muscle weakness resulting from less or no activity due to pain and disability caused by tennis elbow. It has been assumed that the underlying mechanism of pain relief secondary to friction massage may be due to modulation of pain impulses at the spinal cord level [15] [16].

Use of a wrist splint can be helpful because it places the extensor muscles in a position of rest and prevents maximal muscle contraction. Counterforce bracing (tennis elbow strap) is alternative orthotic that can be used during activity to unload the area of muscle origin at the elbow. Deep tissue friction massage helps to release underlying adhesions and promote improved circulation to the area. Flexibility, strength, and endurance of the wrist extensor muscle group can be achieved through a graded program. ROM for wrist flexion/extension and pronation/supination should be achieved prior to strengthening exercises. Strength and grip training should progress from isometric, concentric to eccentric contractions of the wrist extensors [17] [18].

Passive stretching should be applied to the wrist extensors with the elbow extended. Patients are instructed that these exercises may cause discomfort at first but should not cause persistent pain. The offending activities are eliminated and the athlete is placed on a relative rest restriction [19] overload of the wrist extensors, which is considered to be a major pathogenic factor in lateral epicondylitis, and can be reduced by orthoses. There is a significant difference among biomechanical effect of orthoses [8] application of a wrist orthosis which reduces electrical activity of the wrist extensors to be less than anticipated during lifting [20] [21]. The aim of the current study was to compare the effect of deep friction massage versus stretching of wrist extensor muscles in the treatment of patients with tennis elbow.

\section{Materials and Methods}

\subsection{Subjects}

The study included 40 patients (22 males and 18 females). They were diagnosed with lateral epicondylitis at outclinic of orthopedic surgery, Kasr Elaini hospital. All of them were suffering from pain, limitation of ROM of wrist extension and flexion and hand grip weakness. They were divided into 2 groups. The first group followed a physical therapy program with a focus on deep friction massage on the upper attachments of wrist ex- 
tensor muscles, whereas, the physical therapy program of the second group focused on stretching of wrist extensors.

\subsection{Instrumentations}

1) Universal goniometer to measure ROM of wrist extension and flexion [22].

2) Visual analogue scale to measure the pain severity [23].

3) Squeezing sphygmomanometer to test the power of hand grip [24].

\subsection{Procedures}

The patients signed an informed consent form, and were informed about the whole procedures before testing and training.

\subsection{Treatment Procedures}

The first group underwent the following physical therapy program:

1) Deep friction massage (5 minutes at the site of upper attachment of the common extensors of the wrist), 2) Ultrasonic therapy (3 minutes, $1.5 \mathrm{w} / \mathrm{sec}^{2}$ in continuous mode), 3) Using of wrist splint (elastic bandage in functional position of the hand) during treatment period to prevent full flexion or extension and so to avoid over stress on the upper attachment of the common extensors of the wrist, and at the same time allow the movement of the wrist and hand at the same time. The treatment continued for three sessions per week for 6 weeks.

The second group, submitted to the following physical therapy program:

1) Exercise in the form of stretching of wrist extensors (5 repetitions, 30 seconds in position of stretching, 30 seconds in position of release (no stretching), with elbow extended), 2) Ultrasonic therapy (3 minutes, $1.5 \mathrm{w} / \mathrm{sec}^{2}$ in continuous mode), 3) Using of wrist splint (elastic bandage in functional position of the hand) during treatment period to prevent full flexion or extension and so to avoid over stress on the upper attachment of the common extensors of the wrist, and at the same time allow the movement of the wrist and hand at the same time. The treatment continued for three sessions per week for 6 weeks.

\subsection{Assessment Procedures}

All the patients were assessed before treatment and reassessed after 6 weeks using:

1) Universal goniometer to measure ROM of wrist extension and flexion. The fixed arm of the goniometer was placed in parallel to the forearm and the movable arm in parallel to the ulnar side of the hand and little finger in 0 position then the subject were asked to flex and extend the wrist. Each movement was recorded for 3 times to get mean ROM) of wrist flexion and extension.

2) Visual analogue scale (VAS) to measure the pain which is represented from (0) grade to (10) grade, with zero means no pain and ten means intolerable pain, The subjects were asked to indicate the level of pain by placing a dash at the appropriate level on the $10 \mathrm{~cm}$ horizontal line.

3) Squeezing sphygmomanometer to test the power of handgrip. The change in pressure of sphygmomanometer was recorded before and after the treatment program.

\subsection{Data Analysis}

Minimum and maximum values, mean and standard deviation (SD) were used for descriptive statistics. The pre-and post- treatment values in the same group were compared using two tail-paired t-test, and the difference between two groups was compared using two tail-unpaired t-test at a confidence level of 0.05 .

\section{Results}

\section{Treatment with deep friction massage}

There was a significant improvement of pain. Mean VAS values changed from (6.85 \pm 0.93$)$ to (4.3 \pm 0.97$)$. The ROM of wrist flexion increased from ( $58.5 \pm 4.27)$ to $(67.95 \pm 3.89)$, and ROM of wrist extension increased from (40.8 \pm 7.95$)$ to (53.35 \pm 4.59$)$. The difference of hand grip after treatment was from (26.59 \pm 3.65$)$ to (30 \pm 3.5 ), but this difference was not statistically significant (Table 1, Figure 1). 


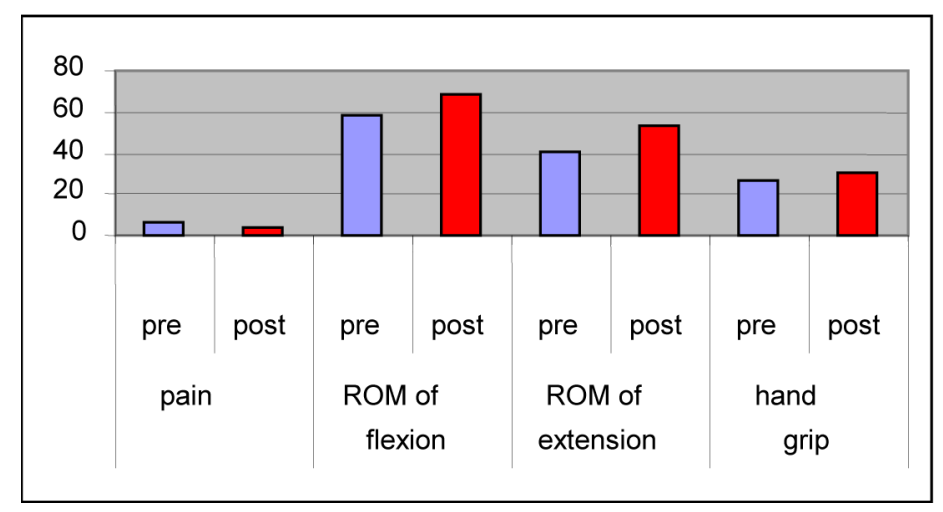

Figure 1. The mean values of pain, wrist and hand grip in first group.

Table 1. Pre and post values of pain, ROM of wrist flexion, ROM of wrist extension, and hand grip, in first group.

\begin{tabular}{|c|c|c|c|c|c|c|c|c|}
\hline & \multicolumn{2}{|c|}{ pain } & \multicolumn{2}{|c|}{ ROM of flexion } & \multicolumn{2}{|c|}{ ROM of extension } & \multicolumn{2}{|c|}{ hand grip } \\
\hline & pre & post & pre & post & pre & post & pre & post \\
\hline Min & 6 & 3 & 50 & 60 & 21 & 40 & 20 & 25 \\
\hline Max & 8 & 6 & 67 & 75 & 50 & 60 & 35 & 40 \\
\hline Mean & 6.85 & 4.3 & 58.5 & 67.95 & 40.8 & 53.35 & 26.59 & 30 \\
\hline SD & 0.93 & 0.97 & 4.27 & 3.89 & 7.95 & 4.59 & 3.65 & 3.5 \\
\hline P. value & \multicolumn{2}{|c|}{12.07} & \multicolumn{2}{|c|}{13.19} & \multicolumn{2}{|c|}{8.48} & \multicolumn{2}{|c|}{5.87} \\
\hline
\end{tabular}

The results of the second group: There was a significant improvement of pain. Mean VAS values changed from $(7.1 \pm 0.78)$ to $(2.55 \pm 0.82)$. The ROM of wrist flexion increased from (60.3 \pm 5.26$)$ to (73.2 \pm 4$)$, and ROM of wrist extension increased from (42.35 \pm 5.23$)$ to (58.6 \pm 4.39$)$. The difference of hand grip after treatment was from (27.04 \pm 3.84$)$ to (53.4 \pm 6.2$)$ (Table 2, Figure 2).

\section{Comparison between Both Groups}

There is significant difference between post measures of the first group and post measures of the second group of T. value of pain is 5.55, ROM of wrist flexion (T. value is 5.11), ROM of wrist extension (T. value is 3.88), and hand grip (T. value is 19.09) (Table 3).

\section{Discussion}

The results of this study showed that there was a significant improvement of pain, and ROM of wrist flexion and extension in both groups where the focus of physical therapy was deep friction massage or stretching exercises of wrist extensors, respectively. It can be speculated that the stretching exercise can decrease spasm of the muscles and improve the circulation which decrease the concentration of metabolites, whereas the deep friction massage can modulate the nociceptive impulses at the level of the spinal cord through the "gate control theory" (inhabitation of the A-delta $\mathrm{C}$ fibers which responsible on transmitting the pain by stimulating the large fibers through substantia gelatinosa [25]

This is explained by the following: The centripetal projection into the dorsal horn of the spinal cord from the nociceptive receptor system is inhibited by the concurrent activity (stretching and deep friction massage) of the mechanoreceptors located in the same tissues, leads to increased destruction of pain provoking metabolites, such as Lewis's substances (this metabolite, if present in too high concentration, causes ischaemia and pain), and also produces therapeutic movement by breaking down the strong cross links or adhesions that have been formed(softening the scar tissue and mobilising the cross links between the collagen fibres and surrounding tissues [26]-[29].

Stasinopoulos and Johnson 2004, concluded that, it is a common clinical observation that application of deep 


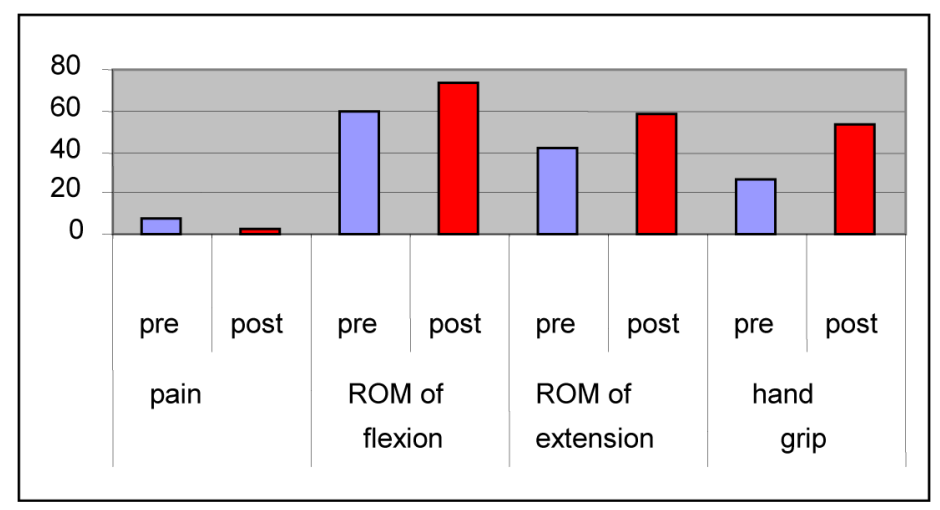

Figure 2. The mean values of pain, wrist and hand grip in second group.

Table 2. Pre and post values of pain, ROM of wrist flexion, ROM of wrist extension,and hand grip, in second group.

\begin{tabular}{|c|c|c|c|c|c|c|c|c|}
\hline & \multicolumn{2}{|c|}{ Pain } & \multicolumn{2}{|c|}{ ROM of flexion } & \multicolumn{2}{|c|}{ ROM of extension } & \multicolumn{2}{|c|}{ Hand grip } \\
\hline & pre & post & pre & post & pre & post & pre & post \\
\hline Min & 6 & 1 & 52 & 65 & 33 & 52 & 20 & 40 \\
\hline Max & 8 & 4 & 70 & 80 & 50 & 65 & 35 & 65 \\
\hline Mean & 7.1 & 2.55 & 60.3 & 73.2 & 42.35 & 58.6 & 27.05 & 53.4 \\
\hline SD & 0.78 & 0.82 & 5.26 & 4 & 5.23 & 4.39 & 3.84 & 6.2 \\
\hline P. value & \multicolumn{2}{|c|}{16.48} & \multicolumn{2}{|c|}{11.72} & \multicolumn{2}{|c|}{11.4} & \multicolumn{2}{|c|}{18.1} \\
\hline
\end{tabular}

Table 3. The mean values of post test of pain, ROM of wrist flexion, ROM of wrist extension, and hand grip, in both groups.

\begin{tabular}{cccccccccc}
\hline & \multicolumn{2}{c}{ Pain } & \multicolumn{2}{c}{ ROM of flexion } & \multicolumn{2}{c}{ ROM of extension } & \multicolumn{2}{c}{ Hand grip } \\
\hline & $1^{\text {st }}$ gr. & $2^{\text {nd }}$ gr. & $1^{\text {st }}$ gr. & $2^{\text {nd }}$ gr. & $1^{\text {st }}$ gr. & $2^{\text {nd }}$ gr. & $1^{\text {st }}$ gr. & $2^{\text {nd }}$ gr. \\
\hline Min & 3 & 1 & 60 & 65 & 40 & 52 & 25 & 40 \\
Max & 6 & 4 & 75 & 80 & 60 & 65 & 40 & 65 & 53.4 \\
Mean & 4.3 & 2.55 & 67.95 & 73.2 & 53.35 & 58.6 & 30 & 3.5 & 6.2 \\
PD & 0.97 & 0.82 & 3.89 & 4 & 4.59 & 4.39 & & & \\
\end{tabular}

friction massage leads to immediate pain relief. The patient experiences a numbing effect during the session, and reassessment immediately after wards shows reduction in pain and increase in strength and mobility [27]. It is suggested that ultrasonic therapy can relax the tense soft-tissues through its micromassage effect [29]. Our results are inline with previous studies which have shown that physical therapy treatment methods of stretching exercise, deep friction massage, and ultrasonic therapy are effective in relieving pain in the management of tennis elbow [27] [29]. The improvement of ROM of wrist flexion and extension can be due to pain reduction which consequently improved the muscle function.

There was no significant improvement of hand grip in the first group due to overtension of the wrist extensor muscles, which is considered to be a major pathogenic factor in lateral epicondylitis, and repeated stress from the movement of the wrist joint. At the same time, there was significant improvement of hand grip in the second group as stretching exercises helped to regain the length of extensor muscles which in turn allowed maximal muscle contraction of wrist flexors, and thereby decreased overload of the wrist extensors [30].

In comparison of results of both groups, there is a significant improvement of pain, improvement of ROM of wrist flexion and extension and hand grip in second group which using stretching due to decreasing and control the repeated over tension on the common extensors of the wrist during stretching, and allows maximal muscle contraction of hand grip [31] [32]. 
The tension created through lengthening (stretching) allows the formation of new fibrous tissue at the musculotendinous unit, making it more resistant to damage. Other possible explanations for the positive effects on tendonitis include "lengthening" of the muscle-tendon unit, which might result in less strain during elbow joint motion, or "loading" of the muscle-tendon unit, which might increase the tensile strength of the tendon and cause hypertrophy of the muscle belly [31] [32].

The results of the current study showed that the improvement in the second group was significantly more than the first group regarding pain, ROM of wrist flexion and extension, and handgrip force. This is explained by the assumption that the stretching exercises of common extensors of the wrist helped to lengthen the muscles and the use of wrist splint helped in unloading these muscles during movements, resulting in improved ROM of wrist flexion and extension and handgrip force.

\section{Conclusion}

This study shows that stretching is important to be included in the program of management of tennis elbow patients where it decreases overload of the wrist extensors and pain. It regains the length of extensor muscles, allows maximal muscle contraction of wrist flexors and power of handgrip. The results of this study suggest that stretching exercises of common extensors of the wrist can be effective for the management of tennis elbow patients.

\section{References}

[1] Sran, M., Souvlis, T., Vicenzino, B. and Wright, A. (2002) Characterisation of Chronic Lateral Epicondylalgia Using the McGill Pain Questionnaire, Visual Analog Scales, and Quantitative Sensory Tests. Pain Clinic, 13, 251-260. http://dx.doi.org/10.1163/156856901753702429

[2] Shamsoddini, A., Hollisaz, M.T., Hafezi, R. and Amanellahi, A. (2010) Immediate Effects of counterforce Forearm Brace on Grip Strength and Wrist Extension Force in Patients with Lateral Epicondylosis. Hong Kong Journal of Occupational Therapy, 20, 8-12. http://dx.doi.org/10.1016/S1569-1861(10)70052-8

[3] Smidt, N., van der Windt, D.A.W.M., Assendelft, W.J.J., Devillé, W.L.J.M., Korthals-de Bos, I.B.C. and Bouter, L.M. (2002) Corticosteroid Injections, Physiotherapy, or a Wait-and-See Policy for Lateral Epicondylitis: A Randomised Controlled Trial. The Lancet, 359, 657-662. http://dx.doi.org/10.1016/S0140-6736(02)07811-X

[4] Shamsoddini, A. and Hollisaz, M.T. (2013) Effects of Taping on Pain, Grip Strength and Wrist Extension Force in Patients with Tennis Elbow. Trauma Monthly, 18, 71-74. http://dx.doi.org/10.5812/traumamon.12450

[5] Ivković, A., Franić, A., Bojanić, I. and Pećina, M. (2007) Overuse Injuries in Female Athletes. Croatian Medical Journal, 48, 767-778.

[6] Chesterton, L.S., van der Windt, L.S., Sim, J., Lewis, M., Mallen, C.D., Mason, E.E., Warlow, C., Vohora, K. and Hay, E.M. (2009) Transcutaneous Electrical Nerve Stimulation for the Management of Tennis Elbow: A Pragmatic Randomized Controlled Trial: the TATE Trial (ISRCTN 87141084). BMC Musculoskeletal Disorders, 10, 156. http://dx.doi.org/10.1186/1471-2474-10-156

[7] Olaussen, M., Holmedal, Ø., Lindbæk, M. and Brage, S. (2009) Physiotherapy Alone or in Combination with Corticosteroid Injection for Acute Lateral Epicondylitis in General Practice: A Protocol for a Randomised, Placebo-Controlled Study. BMC Musculoskeletal Disorders, 10, 152. http://dx.doi.org/10.1186/1471-2474-10-152

[8] Haker, E. (1993) Lateral Epicondylalgia: Diagnosis, Treatment and Evaluation. Critical Reviews in Physical and Rehabilitation Medicine, 5, 129-154.

[9] Carol, C. and Garrett, W.E. (1997) Tendon Problems in Athletic Individuals. The Journal of Bone and Joint Surgery A, 79, 138-150.

[10] Boyer, M.I. and Hastings, H. (1999) Lateral Tennis Elbow: “Is There Any Science out There?” Journal of Shoulder and Elbow Surgery, 8, 481-491. http://dx.doi.org/10.1016/S1058-2746(99)90081-2

[11] Wright, A. and Vicenzino, B. (1997) Lateral Epicondylagia: Therapeutic Management. Physical Therapy, 2, 39-48. http://dx.doi.org/10.1179/ptr.1997.2.1.39

[12] Molsberger, A. and Hille, E. (1994) The Analgesic Effect of Acupuncture in Chronic Tennis Elbow Pain. British Journal of Rheumatology, 33, 1162-1165. http://dx.doi.org/10.1093/rheumatology/33.12.1162

[13] Goguin, J.P. and Rush, F. (2003) Lateral Epicondylitis. What Is It Really? Current Orthopaedics, 17, $386-389$. http://dx.doi.org/10.1016/S0268-0890(03)00111-7

[14] Stasinopoulos, D., Stasinopoulou, K. and Johnson, M.I. (2005) An Exercise Programme for the Management of Lateral Elbow Tendinopathy. British Journal of Sports Medicine, 39, 944-947. http://dx.doi.org/10.1136/bjsm.2005.019836 
[15] De Bruijn, R. (1984) Deep Transverse Friction: Its Analgesic Effect. International Journal of Sports Medicine, 5, 3536. http://dx.doi.org/10.1055/s-2008-1025944

[16] Viswas, R., Ramachandran, R. and Korde Anantkumar, P. (2012) Comparison of Effectiveness of Supervised Exercise Program and Cyriax Physiotherapy in Patients with Tennis Elbow (Lateral Epicondylitis): A Randomized Clinical Trial. Scientific World Journal, 2012, Article ID: 939645.

[17] De Smedt, T., de Jong, A., Van Leemput, W., Lieven, D. and Van Glabbeek, F. (2007) Lateral Epicondylitis in Tennis: Update on Aetiology, Biomechanics and Treatment. British Journal of Sports Medicine, 41, 816-819. http://dx.doi.org/10.1136/bjsm.2007.036723

[18] Pettrone, F.A. and McCall, B.R. (2005) Extracorporeal Shock Wave Therapy without Local Anesthesia for Chronic Lateral Epicondylitis. Journal of Bone and Joint Surgery, 87, 1297-1304.

[19] Nirschl, R.P. and Kraushaar, B.S. (1996) Assessment and Treatment Guidelines for Elbow Injuries. The Physician and Sports Medicine, 24, 43-60. http://dx.doi.org/10.3810/psm.1996.05.1340

[20] Hillel, M. and Deborah, L. (2008) Tennis Elbow No More Practical Eccentric and Concentric Exercises to Heal the Pain. Canadian Family Physician, 54, 1115-1116.

[21] Borkholder, C.D., Hill, V.A. and Fess, E.E. (2004) The Efficacy of Splinting for Lateral Epicondylitis: A Systematic Review. Journal of Hand Therapy, 17, 181-199.

[22] Gajdosik, R.L. and Bohannon, R.W. (1987) Clinical Measurement of Range of Motion: Review of Goniometry Emphasizing Reliability and Validity. Physical Therapy, 67, 1867-1872.

[23] Boonstra, A.M., Schiphorst Preuper, H.R., Reneman, M.F., Posthumus, J.B. and Stewart, R.E. (2008) Reliability and Validity of the Visual Analogue Scale for Disability in Patients with Chronic Musculoskeletal Pain. International Journal of Rehabilitation Research, 31, 165-169.

[24] Lusardi, M.M. and Bohannon, R.W. (1991) Hand Grip Strength: Comparability of Measurements Obtained with a Jamar Dynamometer and a Modified Sphygmomanometer. Journal of Hand Therapy, 4, 117-122.

[25] Rivenburgh, D.W. (1992) Physical Modalities in the Treatment of Tendon Injuries. Clinics in Sports Medicine, 11, 645-659.

[26] Goats, G.C. (1994) Massage: The Scientific Basis of an Ancient Art. Part 2. Physiological and Therapeutic Effects. British Journal of Sports Medicine, 28, 153-156. http://dx.doi.org/10.1136/bjsm.28.3.153

[27] Gregory, M., Deane, M. and Mars, M. (2003) Ultrastructural Changes in Untraumatised Rabbit Skeletal Muscle Treated with Deep Transverse Friction. Physiotherapy, 89, 408-416. http://dx.doi.org/10.1016/S0031-9406(05)60074-0

[28] Walker, H. (1984) Deep Transverse Frictions in Ligament Healing. Journal of Orthopaedic \& Sports Physical Therapy, 6, 89-94. http://dx.doi.org/10.2519/jospt.1984.6.2.89

[29] Stasinopoulos, D. and Johnson, M.I. (2004) Cyriax Physiotherapy for Tennis Elbow/Lateral Epicondylitis. British Journal of Sports Medicine, 38, 675-677. http://dx.doi.org/10.1136/bjsm.2004.013573

[30] Schauss, S., Helwig, U., Karpf, M. and Plitz, W. (2000) Effectiveness of Epicondylitis Bandages from the Biomechanical Viewpoint-An Experimental Study. Z Orthop Ihre Grenzgeb, 138, 492-495.

[31] Ivković, A., Franić, M., Bojanić, I. and Pećina, M. (2007) Overuse Injuries in Female Athletes. Croatian Medical Journal, 48, 767-778.

[32] Adrian, E. (2008) Tennis Elbow. Baylor University Medical Center Proceedings, 21, 400-402. 